Chapters 13-18 are more of a miscellany. Radio emission variations are so widely used as quantitative measures of some forms of solar activity that it is necessary to discuss the factors with which they correlate. This has led to a chapter on solar X-ray emission which points out the $X$-ray relations but rather neglects the rest of the ionizing ultra-violet spectrum. The radio phenomena of individual sunspot groups are shown to affect their relations with geomagnetic storms, polar cap events and cosmic ray bursts observed on Earth. These lively modern problems are well discussed. It has also been necessary to discuss the observations of those discrete cosmic sources which can be seen through the extended outer regions of the corona. Such observations make it possible to trace the characteristics of the solar wind most of the way towards the Earth. Finally, reference is mado to the direct radar reflexion obtainable from the Sun.

The book is well set up and well illustrated. It keeps very close to the research problems of the past few years and it does not minimize the difficulties of interpreting the highly varied phenomena. It will be essential for all who are studying either radio astronomy or solar phenomena, and should have a wide use for general reference.

C. W. Alleen

\section{WHAT IS A ROBOT?}

\section{Human Robots in Myth and Science}

By Prof. John Cohen. Pp. $156+16$ plates. (London: Gorge Allen and Unwin, Ltd., 1966.) 35s. net.

DROF. COHEN uses the word 'robot' in the broadest possible sense as any self-regulating artefact which operates without human aid. The first five chapters of Human Robots in Myth and Science are really concerned with mythology and literature which are of interest to the psychologist and the historian rather than to the applied physicist. The applied physicist is concerned with much more precise definitions of terms since he has the task of carrying the industrial revolution into its second stage. The first industrial revolution was the replacement, of human muscle power by heat engines. The second is concerned with the replacement of human attention by automatic devices.

In my opinion the word 'robot' should only be applied to one particular group of automatic devices. Thus we ean distinguish between the computer, automatic control devices, the telearchic machine, specialized machines and the true robot. Basically, the computer can only earry out operations with numbers, although these can be highly complex and very fast and include remembering and taking definite action according to the result of an earlier stage of the calculation. Except when a deliberate random element is built in, the computer is, however, mainly earrying out as accurately as possible and very fast the instructions given to it by men. Automatis control devices can take in, from a small number of instruments, numerical observations of physical factors and operate a numbor of controls on a piece of equipment in a way which has again been built into them by a man. The telearchic machine is simply a device for enabling a man, seated at a control panel in a convenient and comfortable position, to receive sense impressions from a dangerous region and to instruct a machine movement by movement in carrying out complex operations. Specialized machines save labour by enabling a man to do very much faster and more efficiently something that he could do crudely with his hands. This category also includes machines for providing a substitute for a missing part of a man.

The true robot is like a man to the extent that it can do a whole variety of different tasks and in that it receives a certain number of sense improssions so that it can adapt its operations to a limited range of external circumstances. However, it can only (like the computer or the automatic control device) act in precisely tho way in which it has previously been instructed by a man. It can also only carry out movements according to its previously given instructions. This definition of a robot surely gives a clear answer to the question posed in the titlo of the final chapter "Is Man a Robot?". Man differs basically and essontially from a robot in the fact that he can use free will to work out where he wants to go and what he wants to attain and then make his own plan of operetions. In Prof. Cohen's book the ascetic is quoted as an oxample of the most robot-like of humans. I should take exactly the opposite view. The ascetic is the man whose thoughts about his purpose in life have led him to do the actions which are most uneomfortable from the point of view of his physical body.

Neither robots nor computers will ever be able to make an original invention, a really creative work of art, to think of a new scientific hypothesis or to write a good book either on philosophy or on fiction. This is quite simply because not only do they not have free will but they also lack what the author refers to as "the seat of emotion". No creative work of any kind can be done by purely logical processes of juggling concepts or numbers about. It requires the working together of logical understanding and the emotional process of creativeness. It follows that if humans have a capability for having useful emotions and a possibility of free will which can never be built into any machine, then we have a perfect. moral right to treat machines as slaves to serve our purposes. Prof. Cohen discusses the possibility of using animals as slaves, but there is little doubt that in the next 20 years machines can be developed to serve the needs of mankind far more efficiently than animals. There is already in the United States a machine with one hand which can carry out two hundred successive handling operations exactly as it has been instrueted. These operations are stored on magnetic tape.

The big research problem for the applied physicist is to give these robots more advanced ways of being aware of changes in external circumstances and of responding to these changes appropriately.

M. W. Thizing

\section{FORMATION OF ANTIBODIES}

Molecular and Cellular Basis of Antibody Formation Edited by J. Sterzl, with the co-workers of the Immunological Department. (Proceedings of a Symposium held in Prague on June 1-5, 1964.) Pp. 683. (Prague: Publishing House of the Czechoslovak Academy of Sciences, 1965.) $82 \mathrm{~K}$ čs.

M OLECULAR and Cellular Basis of Antibody Formasymposium held in June 1964 and organized by the Immunology Department, Institute of Microbiology, Czechoslovak Academy of Sciences. The meeting was devoted mainly to chemical and biological problems related to antibody formation. The cormmunications are arranged in five sections: (1) nature of immunogenicity (five papers); (2) characterization of antibodies (sixteen papers); (3) primary response in antibody formation (nineteen papers); (4) secondary response in antibody formation (five papers); (5) theories of antibody formation (two papers). The discussion which followed each paper is briefly recorded and each section concludes with a more extended account of exchanges among the eighty-two participants in the symposium.

The first in this series of meetings was held in Prague and Liblice in 1959; the procesdings were published in 1960 and re-issued 2 years later in a book ontitled Mechanisms of Antibody Formation. Comparison of this first book with the present volume reveals how rapidly the understanding of many immunological processes has advanced during the intervening 5 years. This is especially obvious in regard to knowledge of the chemical and physical heterogeneity of immunoglobulin molecules, the structure 